\title{
Factors Influencing in Clinical Decision Making of Nurse: A Systematic Review
}

\author{
Baitus Sholehah ${ }^{\star 1}$, Asti Melani Astari ${ }^{2}$, Rinik Eko Kapti ${ }^{3}$ \\ ${ }^{1}$ Student of Nursing Master Program, Medical Faculty, Universitas Brawijaya, \\ Indonesia \\ ${ }^{2,3}$ Medical Faculty, Universitas Brawijaya, Indonesia \\ Email: gwenenzi@gmail.com
}

\begin{abstract}
Clinical decision making is important for nurses to do. Clinical decision making is a complex process consisting of careful assessment of pathological conditions and patient history and the use of nursing knowledge and learning based on critical thinking experiences. Improper clinical decision making will have fatal consequences for patients This review system was compiled using Proquest. Science Direct and Pubmed databases. Article selection is carried out to identify relevant articles then screening is conducted to adjust the inclusion criteria. 13 articles were obtained in accordance with inclusion criteria and reviewed by using JBI (Joanna Briggs Institute Levels). Data shows that nurses have a very important role in clinical decision making. Nurses' clinical decision making is considered due to the risks faced by patients, thus the nurses should think critically. Clinical decision making for nurses is influenced by several factors including experience, knowledge, environment, team, supervisor support, and professionalism.
\end{abstract}

Keywords: Clinical Decision Making, Nurse, Factors Influencing.

\section{A. INTRODUCTION}

Clinical decision making is important for nurses to do (Thompson et al., 2008). That is because nurses are professionals who have to make clinical decisions on patients (Dunger, Schnell, \& Bausewein, 2017). Nurses' clinical decision making when conducting nursing care will affect effectiveness in clinical practice and affect the safety of patient (Bjørk \& Hamilton, 2011) and should be done precisely and quickly (Johansen \& O'Brien, 2016). Effective clinical decision making depends on the ability to collect, understand and integrate data with a focus on the needs of patients by identifying the clinical situation (Johansen \& O'Brien, 2016).

In 1997 it was reported that at least 98,000 Americans died each year due to errors in clinical decision making by health workers (Kohn, Corrigan, \& Donaldson, 2000). In an international study, $17.7 \%$ of patients experience disabilities and deaths due to inappropriate decision making (Bucknall, 2010). Clinical decision making is a complex process consisting of careful assessment of pathological conditions and patient history and the use of nursing knowledge and experiential learning for critical thinking (Benner, Tanner, \& Chesla, 2009). Nurse clinical decision making is a series of processes performed by nurses to patients including observing the patient's condition, evaluating data obtained from patient examinations and taking appropriate actions to achieve the desired results (Lauri \& Salanterä, 2002). 
Observation of the patient's condition is the initial process of collecting information, identifying problems and obtaining information about the patient's condition (Prescott, Dennis, \& Jacox, 1987). Data evaluation in the clinical decision making process is a problem solving process that focuses on analyzing the situation to take solutions and decide on existing problems (Simamora, 2018). Taking action on the patient is done after the nurse observes the patient's condition and evaluates the data obtained to choose management that is appropriate to the patient's condition and priority problems (Payne, 2015).

The nurse in decision making refers to the ability to make decisions based on experience and information about treatment. Includes the ability to understand medical problems (Carroll, 2010). The nurse's clinical experience has the most influence on the whole decision making process (Bakalis, 2006). Because improper decision making will endanger the lives of patients, thus nurses should be able to think critically (Hosseini, Maleki, Gorji, Khorasani-Zavareh, \& Roudbari, 2018). Based on the presentation of the data above, the writer interested in writing a systematic review with the theme of "Factors influencing in clinical decision making of nurses".

\section{B. METHOD}

This study is a systematic review based on a database of factors influencing in clinical decision making of nurses. This systematic review was prepared using a search strategy by utilizing Proquest, Science Direct and Pubmed databases using Keywords of: Clinical Decision Making of Nursing and Factors Influencing Clinical Decision Making. Before conducting a search on the data base, the author made several settings in the database page by specifying the research year from 2009-2019, English language articles, can be accessed full text and document type is a research article. A total of 564 articles from Proquest, 219 articles from Science Direct and 216 articles from Pubmed. Articles that are relevant to the theme are identified, then screened by reading the title and research abstract by specifying related to factors that influence nurses' decision making and obtained 45 articles and downloaded to be read the full text, then each article is determined whether the article is included. inclusion criteria or exclusion criteria. The number of articles included in the inclusion criteria was 13 articles included in this systematic review. Inclusion criteria that have been established by the authors include:

1. Journal articles published from 2009-2019.

2. Nurses' clinical decision making.

The process of selecting and determining documents was conducted with the PRISMA flowchart. PRISMA flowchart could be seen in Figure 1. Besides this process also uses the JBI level (Joanna Briggs Institute Levels) in 10 articles that had been determined. Based on the appraisal conducted, a summary of the research results shown in Table 1. 


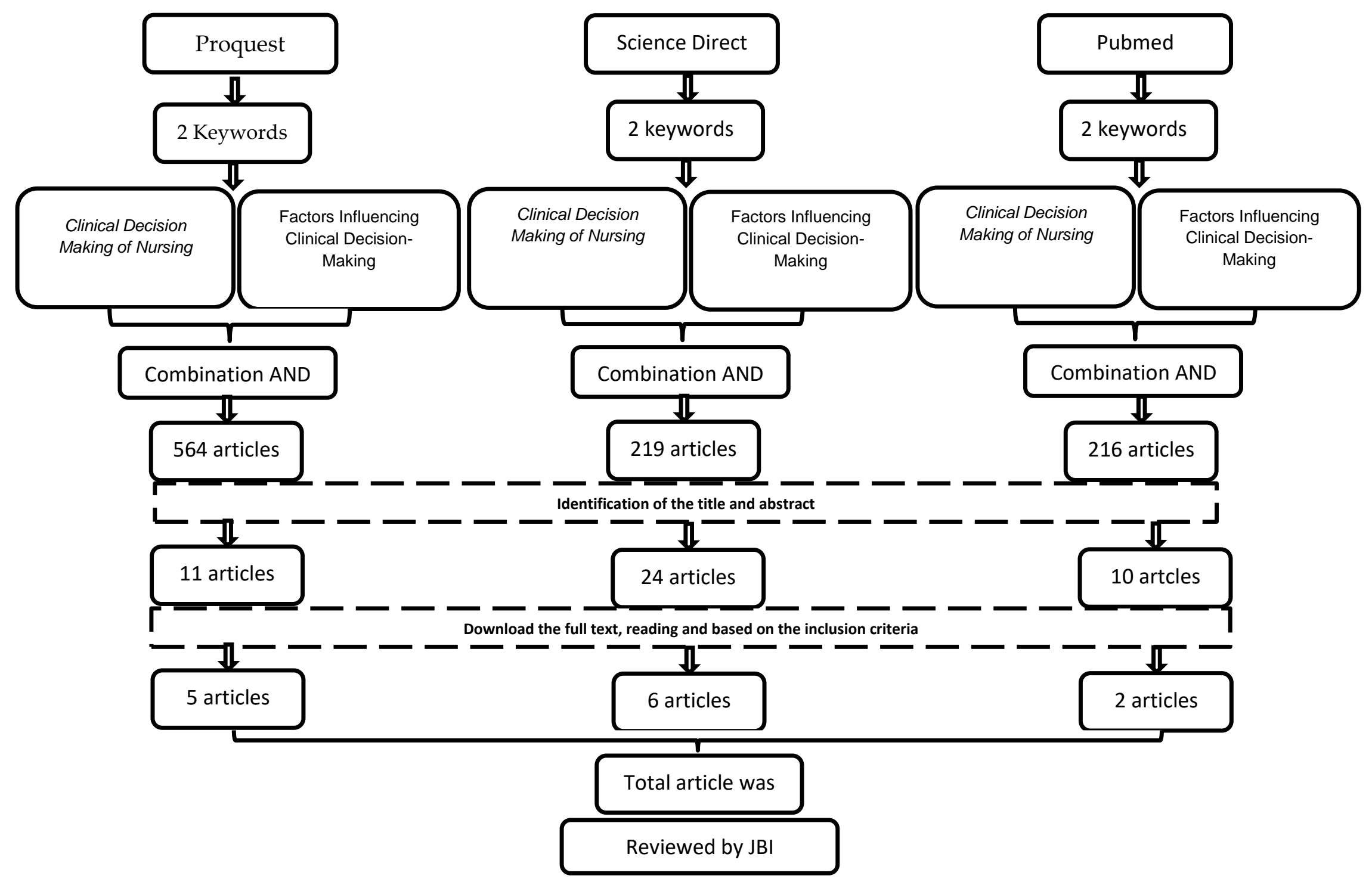

Figure 1. PRISMA Flowchart 
Table 1. Summary of the Research Results

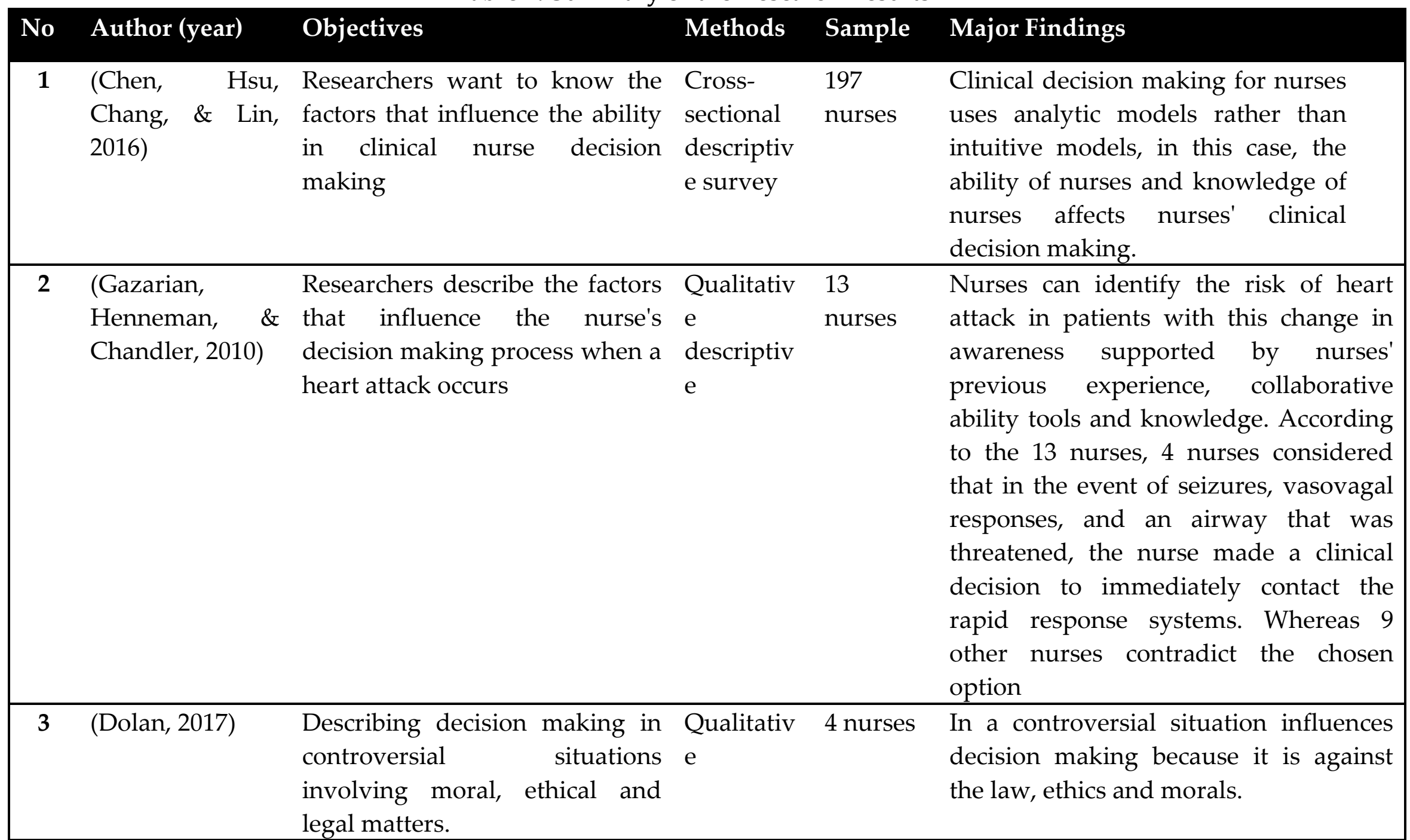




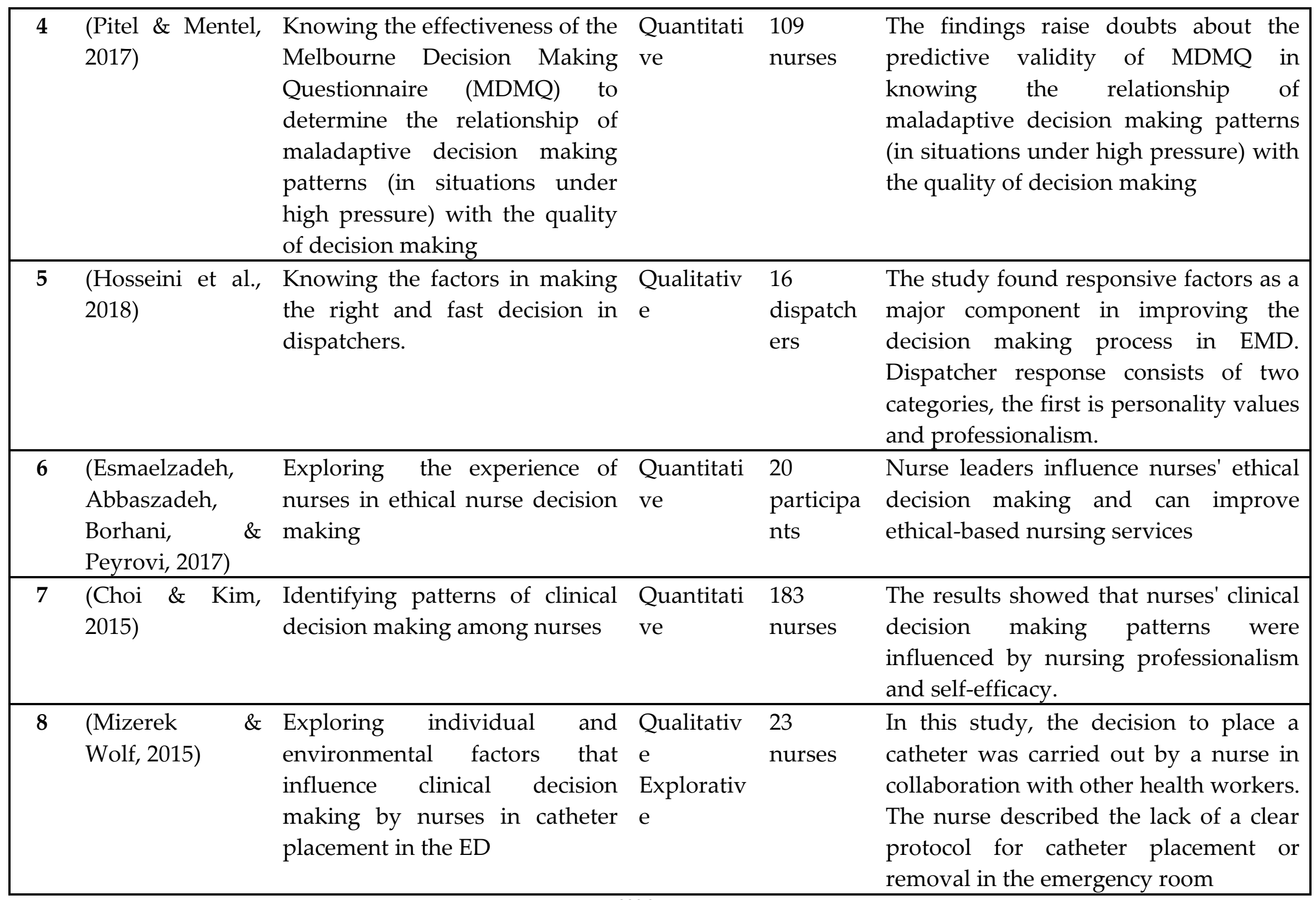




\begin{tabular}{|c|c|c|c|c|c|}
\hline 9 & $\begin{array}{l}\text { (Brummell, } \\
\text { Seymour, \& } \\
\text { Higginbottom, } \\
\text { 2016) }\end{array}$ & $\begin{array}{l}\text { Exploring the experience of } \\
\text { emergency staff in making } \\
\text { decisions to start, continue or } \\
\text { stop resuscitation }\end{array}$ & $\begin{array}{l}\text { Qualitativ } \\
\text { e } \\
\text { ethnograp } \\
\text { hy }\end{array}$ & $\begin{array}{l}13 \\
\text { nurses, } \\
12 \\
\text { medical } \\
\text { and } 2 \\
\text { paramed } \\
\text { ics }\end{array}$ & $\begin{array}{l}\text { Emergency staff decisions regarding } \\
\text { resuscitation use a heuristic decision- } \\
\text { making approach that is fast and } \\
\text { economical }\end{array}$ \\
\hline 10 & $\begin{array}{l}\text { (Fry } \\
\text { MacGregor, } \\
2014 \text { ) }\end{array}$ & $\begin{array}{l}\text { Exploring nurses' confidence in } \\
\text { making clinical decisions }\end{array}$ & $\begin{array}{l}\text { Qualitativ } \\
\mathrm{e}\end{array}$ & $\begin{array}{l}52 \\
\text { participa } \\
\text { nts }\end{array}$ & $\begin{array}{l}\text { Self-confidence is a factor that supports } \\
\text { the nurse's ability to solve problems } \\
\text { and think critically to determine the } \\
\text { best way to make decisions }\end{array}$ \\
\hline 11 & $\begin{array}{l}(\mathrm{Wu}, \text { Yang, Liu, } \\
\& Y e, 2016)\end{array}$ & $\begin{array}{l}\text { Investigating the factors that } \\
\text { influence clinical decision } \\
\text { making }\end{array}$ & $\begin{array}{l}\text { Quantitati } \\
\text { ve with } \\
\text { cross- } \\
\text { sectional } \\
\text { research } \\
\text { design } \\
\end{array}$ & $\begin{array}{l}216 \\
\text { nurses }\end{array}$ & $\begin{array}{l}\text { In this study it was found that the best } \\
\text { nurses are nurses who have the ability } \\
\text { to self-manage, in this case the level of } \\
\text { education, experience and structural } \\
\text { strength has a positive effect in making } \\
\text { clinical nurses' decision making }\end{array}$ \\
\hline 12 & $\begin{array}{l}\text { (Wilson, Talsma, } \\
\text { \& Martyn, 2011) }\end{array}$ & $\begin{array}{l}\text { Describing the behavior of } \\
\text { effective decision making from } \\
\text { the perspective of the nurse } \\
\text { financial manager, nurse } \\
\text { manager and nurse staff }\end{array}$ & $\begin{array}{l}\text { Qualitativ } \\
\mathrm{e}\end{array}$ & $\begin{array}{l}24 \\
\text { nurses }\end{array}$ & $\begin{array}{l}\text { In this study found } 5 \text { themes that } \\
\text { emerged in decision-making behavior, } \\
\text { namely reason, communication, } \\
\text { flexible, assertive and future awareness. } \\
\text { In this case the nurse of the financial } \\
\text { manager is described by an attentive } \\
\text { nurse. }\end{array}$ \\
\hline
\end{tabular}




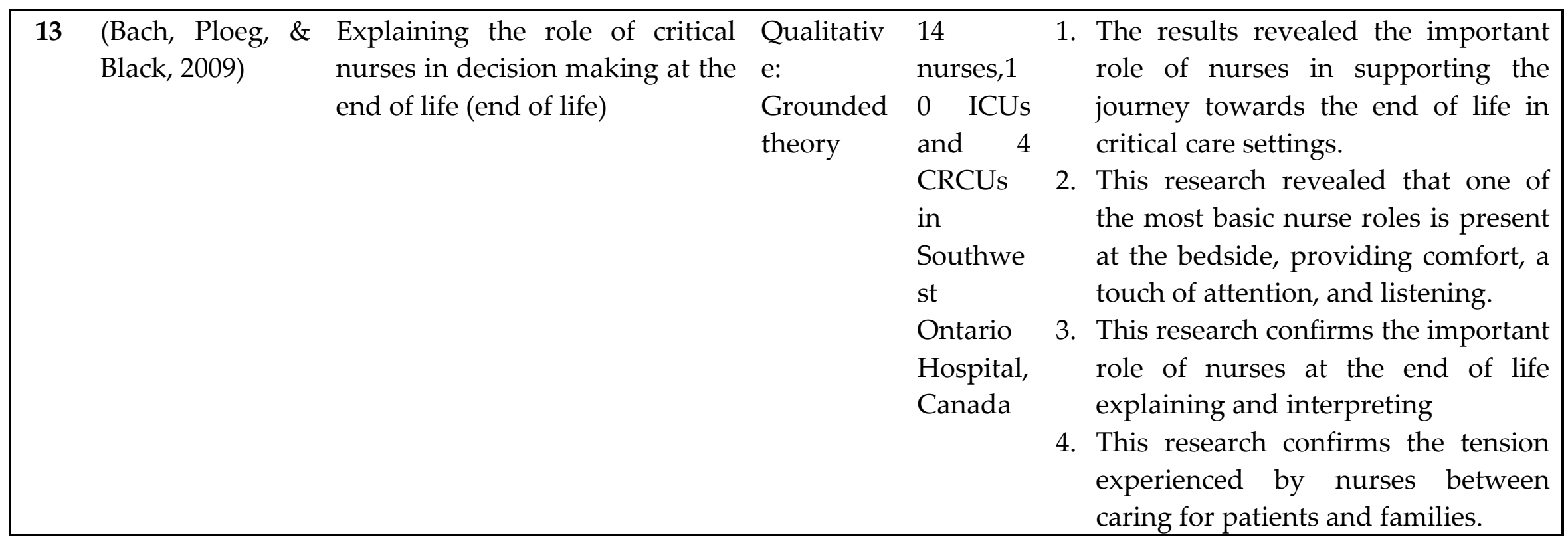




\section{RESULT AND DISCUSSION}

Nurses have a very important role in clinical decision making and have a variety of different references in decision making patterns. Because nurses who make clinical decisions will affect the patient's situation and when making clinical nurse decisions based on several factors such as knowledge, experience, professionalism and collaborative. Based on a cross sectional descriptive survey to determine the extent to which nurses' abilities in decision making by involving nurse practitioners as many as 179 obtained clinical decision making results on nurses using analytical models rather than intuitive models in this case the ability of nurses' knowledge affects nurses' clinical decision making (Chen et al., 2016). Other studies that illustrate the factors that influence the decision making process used by nurses in identifying emergencies such as heart attacks involving 13 nurses have found results: nurses can identify the risk of heart attacks in patients with changes in consciousness this is supported by the experience of previous nurses, equipment collaborative ability and knowledge. Of the 13 nurses, 4 nurses considered that in the event of seizures, vasovagal responses, and an airway that was threatened, the nurse made a clinical decision to immediately contact the rapid response systems. While 9 other nurses contradicted the option considered (Gazarian et al., 2010).

Research on decision making in controversial situations involving moral, ethical and legal matters involving 4 nurses and 16 controversial situations results in controversial situations resulting in conflicting moral, ethical and legal pressures that influence decision making (Dolan, 2017). Research to determine the relationship between maladaptive decision making / under pressure with the quality of decision making using the Melbourne Decision Making Questionnaire (MDMQ) and Subjective Performance Evaluation of Decision-Making Quality (SPEDM). By involving 16 dispatchers in 7 Emergency Medical Dispatchers (EMD), it was found that a good response as a major component in improving the decision making process in EMD, the response dispatcher consisted of two categories, the first being personality values and professionalism (Hosseini et al., 2018). In another study to explore the experience of nurse leaders in strengthening ethical decisions to nurses by involving 20 participants and the results obtained that leaders can strengthen ethical nursing decision making (Esmaelzadeh et al., 2017). The research aims to identify patterns of decision making among nurses by involving 183 nurses and the results show that nurses' clinical decision making patterns are influenced by nursing professionalism and self-efficacy (Choi \& Kim, 2015).

The research to find out about individual and environmental factors that can influence clinical decision making regarding the placement and maintenance of urinary catheters by emergency nurses involving 23 nurses and the results show that decision making is under the collaborative nursing field (Mizerek \& Wolf, 2015). The research to 
explore how emergency staff make decisions to start, continue or stop resuscitation by involving as many as 13 nurses, as many as 12 medical doctors and as many as 2 . paramedics The results of emergency staff decisions regarding resuscitation actions using heuristic decision decisions are fast and low-cost (Brummell et al., 2016). Another research to explore the confidence of emergency nurses in nursing practice and decision making involving 52 participants found that self-confidence is a factor that supports nurses' ability to solve problems and think critically to determine the best way to make decisions (Fry \& MacGregor, 2014). The research of (Wu et al., 2016) which aims to investigate the factors that influence clinical decision making using quantitative methods with cross-sectional research design involving 216 nurses found that the best nurses are nurses who have the ability to self-manage, in this case the level of education, experience and structural strength have a positive effect on make clinical nurse decision making.

The research of (Wilson et al., 2011) which aims to describe effective decisionmaking behavior from the perspective of nurses financial managers, nurse managers and nursing staff involving 24 nurses found 5 themes that emerge in decision-making behavior namely reason, communication, flexible, decisive and future awareness. In this case the nurse of the financial manager is described by an attentive nurse. While the research of (Bach et al., 2009) involving 14 ICU nurses and 4 CRCU nurses in southwest Ontario, Canada, the first results were obtained, nurses had an important role in supporting the journey towards the end of life in critical care settings. The second revealed that one of the most basic nurse roles is present at the bedside, providing comfort, a touch of attention, and listening. Third confirms the important role of nurses at the end of life explaining and interpreting and fourth emphasizes the tension experienced by nurses between caring for patients and families.

\section{CONCLUSION}

The provision of nursing care is conducted by nurses to patients. Clinical decision making should be done with critical and professional thinking, thus the clinical action for patient could be done without causing fatally things. Nurse clinical decision making is influenced by several factors including: experience, knowledge, environment, team, supervisor support, and professionalism.

\section{REFERENCES}

1. Bach, V., Ploeg, J., \& Black, M. (2009). Nursing roles in end-of-life decision making in critical care settings. Western Journal of Nursing Research, 31(4), 496-512. https://doi.org/10.1177/0193945908331178

2. Bakalis, Ni. (2006). Clinical decision-making in Cardiac nursing: a review of the literatur. Art E Science Cardiology Focus, 21(12). 
3. Benner, P., Tanner, C. A., \& Chesla, C. A. (2009). Expertise in Nursing Practice Caring, Clinical Judgment $\mathcal{E}$ Ethics. (A. Graubard, Ed.) (second). New York: Springer Publishing Company.

4. Bjørk, I. T., \& Hamilton, G. A. (2011). Clinical Decision Making of Nurses Working in Hospital Settings. Nursing Research and Practice, 2011, 1-8. https://doi.org/10.1155/2011/524918

5. Brummell, S. P., Seymour, J., \& Higginbottom, G. (2016). Cardiopulmonary resuscitation decisions in the emergency department: An ethnography of tacit knowledge in practice. Social Science and Medicine, 156, 47-54. https://doi.org/10.1016/j.socscimed.2016.03.022

6. Bucknall, T. K. (2010). Medical error and decision making: Learning from the past and present in intensive care. Australian Critical Care, 23(3), 150-156. https://doi.org/10.1016/j.aucc.2010.06.001

7. Carroll, D. W. (2010). Assessment of capacity for medical decision making. Journal of Gerontological Nursing, 36(5), 47-52. https://doi.org/10.3928/00989134-20100303-03

8. Chen, S. L., Hsu, H. Y., Chang, C. F., \& Lin, E. C. L. (2016). An exploration of the correlates of nurse practitioners' clinical decision-making abilities. Journal of Clinical Nursing, 25(7-8), 1016-1024. https://doi.org/10.1111/jocn.13136

9. Choi, M., \& Kim, J. (2015). Relationships Between Clinical Decision-Making Patterns and Self-Efficacy and Nursing Professionalism in Korean Pediatric Nurses. Journal of Pediatric Nursing, 30(6), e81-e88. https://doi.org/10.1016/j.pedn.2015.07.001

10. Dolan, C. (2017). Moral, Ethical, and Legal Decision-making in Controversial NP??Practice Situations. Journal for Nurse Practitioners, 13(2), e57-e65. https://doi.org/10.1016/j.nurpra.2016.10.017

11. Dunger, C., Schnell, M. W., \& Bausewein, C. (2017). Nurses' decision-making in ethically relevant clinical situations using the example of breathlessness: Study protocol of a reflexive grounded theory integrating Goffman's framework analysis. BMJ Open, 7(2), 1-8. https://doi.org/10.1136/bmjopen-2016-012975

12. Esmaelzadeh, F., Abbaszadeh, A., Borhani, F., \& Peyrovi, H. (2017). Strengthening ethical decision-making: The experience of Iranian nurses. Nursing Management, 24(6), 33-39. https://doi.org/10.7748/nm.2017.e1610

13. Fry, M., \& MacGregor, C. (2014). Confidence and impact on clinical decisionmaking and behaviour in the emergency department. Australasian Emergency Nursing Journal, 17(3), 91-97. https://doi.org/10.1016/j.aenj.2014.03.003

14. Gazarian, P. K., Henneman, E. A., \& Chandler, G. E. (2010). Nurse decision making in the prearrest period. Clinical Nursing Research, 19(1), 21-37. https://doi.org/10.1177/1054773809353161

15. Hosseini, S. M. R., Maleki, M., Gorji, H. A., Khorasani-Zavareh, D., \& Roudbari, M. (2018). Factors affecting emergency medical dispatchers' decision-making: A 
qualitative study. Journal of Multidisciplinary Healthcare, 11, 391-398. https://doi.org/10.2147/JMDH.S159593

16. Johansen, M. L., \& O’Brien, J. L. (2016). Decision Making in Nursing Practice: A Concept Analysis. Nursing Forum, 51(1), 40-48. https://doi.org/10.1111/nuf.12119

17. Kohn, Corrigan, J., \& Donaldson, M. (2000). Errors in Health Care A Leading Cause of Death and Injury - To Err is Human - NCBI Bookshelf. Retrieved from www.ncbi.nlm.nih.gov/books/NBK225187/box/bbb00001/?report=objectonly

18. Lauri, S., \& Salanterä, S. (2002). Developing an instrument to measure and describe clinical decision making in different nursing fields. Journal of Professional Nursing, 18(2), 93-100. https://doi.org/10.1053/jpnu.2002.32344

19. Mizerek, E., \& Wolf, L. (2015). To Foley or Not To Foley: Emergency Nurses' Perceptions of Clinical Decision Making in the Use of Urinary Catheters in the Emergency Department. Journal of Emergency Nursing, 41(4), 329-334. https://doi.org/10.1016/j.jen.2014.09.009

20. Payne, L. K. (2015). Toward a Theory of Intuitive Decision-Making in Nursing. Nursing Science Quarterly, 28(3), 223-228. https://doi.org/10.1177/0894318415585618

21. Pitel, L., \& Mentel, A. (2017). Decision-making styles and subjective performance evaluation of decision-making quality among hospital nurses. Studia Psychologica, 59(3), 217-231. https://doi.org/10.21909/sp.2017.03.742

22. Prescott, P. A., Dennis, K. E., \& Jacox, A. K. (1987). Clinical Decision Making of Staff Nurses. Image: The Journal of Nursing Scholarship, 19(2), 56-62. https://doi.org/10.1111/j.1547-5069.1987.tb00591.x

23. Simamora, N. U. R. F. (2018). Proses Pengambilan Keputusan dalam Kperawatan dengan Konsep Berfikir Kritis.

24. Thompson, C., Dalgleish, L., Bucknall, T., Estabrooks, C., Hutchinson, A. M., Fraser, K., ... Saunders, J. (2008). The Effects of Time Pressure and Experience on Nurses' Risk Assessment Decisions. Nursing Research, 57(5), 302-311.

25. Wilson, D. S., Talsma, A. N., \& Martyn, K. (2011). Mindful staffing: A Qualitative description of charge nurses' Decision-Making behaviors. Western Journal of Nursing Research, 33(6), 805-824. https://doi.org/10.1177/0193945910396519

26. Wu, M., Yang, J., Liu, L., \& Ye, B. (2016). An Investigation of Factors Influencing Nurses' Clinical Decision-Making Skills. Western Journal of Nursing Research, 38(8), 974-991. https://doi.org/10.1177/0193945916633458 